\title{
Quinine: not a safe drug for treating nocturnal leg cramps
}

\author{
David B. Hogan MD \\ Author audio interview: www.cmaj.ca/site/podcasts
}

See also research article on page 248 and at www.cmaj.ca/lookup/doi/10.1503/cmaj.140497

I

$\mathrm{n}$ a linked research article, Garrison and colleagues ${ }^{1}$ report on the seasonal variability of nocturnal leg cramps. They found that new quinine prescriptions in the province of British Columbia and Internet searches using the term "leg cramps" in the United States both showed a sinusoidal pattern, with a midsummer peak and a midwinter dip. I don't intend to question this novel finding or speculate on the mechanism underlying the apparent seasonality of the condition. Instead, I will focus on the role of quinine in the management of this common condition.

Quinine sulfate at a dose of $200-300 \mathrm{mg}$ at night has been used for many years to treat nocturnal leg cramps. Usually idiopathic, these muscle cramps are common, particularly in older patients. Quinine may help by decreasing the excitability of the motor end-plate and increasing the muscle refractory period. ${ }^{2}$ A number of drugs have been proposed for the treatment of nocturnal leg cramps. Two systematic reviews published within the last five years both concluded that quinine is modestly effective (reduces cramp frequency by about a quarter, cramp intensity by a tenth and number of days by a fifth). ${ }^{3,4}$ Other pharmacologic measures were found to be either possibly effective (vitamin B complex, naftidrofuryl, calcium-channel blockers) or likely not effective (gabapentin, magnesium). ${ }^{3}$

A variety of adverse effects can occur with the usual therapeutic doses of quinine, including cinchonism (marked by tinnitus, high-tone hearing loss, photophobia and other visual disturbances, dysphoria, headache, nausea, vomiting, sweating, dizziness and postural hypotension), hypoglycemia (from the drug's stimulatory effect on pancreatic $\beta$ cells; most common in the treatment of severe malaria), hypotension (usually related to intravenous infusion of the drug), hearing and visual disturbances (including irreversible loss), gastrointestinal symptoms, cutaneous effects, conduction abnormalities (mild prolongation of the corrected QT interval, which is rare unless plasma levels are elevated), arrhyth- mias and hemolysis (from hypersensitivity or in patients with G6PD deficiency). ${ }^{2,3}$

Of particular concern is the potential for rare but serious hematologic adverse effects (i.e., immune thrombocytopenic purpura and drugmediated thrombotic microangiopathy). In a study of Medicare claims data, the incidence per 1000 person-years with quinine was 1.67 for immune thrombocytopenic purpura and 0.23 for thrombotic microangiopathy. The incidence rate ratios were 4.2 (95\% confidence interval [CI] 2.5-6.5) and 6.9 (95\% CI 1.3-24.0), respectively, compared with diltiazem. ${ }^{5}$ Intentional or inadvertent overdose can cause serious and even fatal arrhythmias. ${ }^{2}$ Severe drug interactions with aluminum-containing antacids, cholinesterase inhibitors, cimetidine, digoxin, neuromuscular blocking agents, warfarin and other agents can take place. ${ }^{2}$ Quinine is contraindicated in patients with a known hypersensitivity, a history of immune thrombocytopenic purpura or thrombotic microangiopathy, G6PD deficiency, tinnitus, optic neuritis, prolonged QT interval or myasthenia gravis. As of Sept. 30, 2010, Health Canada had received 71 reports of serious adverse reactions suspected of being associated with quinine use (41 were either life threatening or required hospital admission). ${ }^{6}$

Although quinine is modestly effective, concerns regarding potential adverse effects have tempered enthusiasm about its use for nocturnal leg cramps. In 2009, the US Food and Drug
Competing interests: None declared.

This article was solicited and has not been peer reviewed.

Correspondence to: David Hogan, dhogan@ucalgary.ca

CMAJ 2015. DOI:10.1503 /cmaj.150044 
Administration (FDA) explicitly noted an unfavourable risk-benefit ratio for quinine when used for leg cramps. ${ }^{5}$ Because of continued reports of serious adverse effects from this offlabel use, the FDA in 2010 launched a riskmanagement plan about its use for leg cramps. ${ }^{5}$ In addition to a letter warning practitioners of the risk of serious and life-threatening hematologic effects, the plan required that patients be given a medication guide explaining what quinine is approved for and its potential adverse effects. The same year, practice guidelines for American neurologists on the symptomatic management of muscle cramps concluded that, although likely effective, quinine should be avoided for routine use because of the potential for toxic effects. ${ }^{3}$

Quinine does not have Health Canada approval for the treatment of nocturnal leg cramps, yet it is widely used for this indication. In the linked research article, data underlying Garrison and colleagues' analyses show 340-576 new and 3430-4372 refilled quinine prescriptions per month in British Columbia, presumably for nocturnal leg cramps, between November 2006 and October 2007 inclusive. ${ }^{1}$ This extent of offlabel use of quinine can be decreased by appropriate action. In response to the advice and action described in the preceding paragraph, the prevalent use of quinine in the US decreased by 99\% during 2006-2012, from 419675 to 6036 individuals. $^{5}$

A systematic review of nonpharmacologic approaches (e.g., stretching) for leg cramps concluded there was limited evidence supporting their use. ${ }^{7}$ However, a six-week randomized trial with concealed allocation and intention-to-treat analysis published after the systematic review showed significant decreases in both the frequency (mean difference 1.2 cramps [95\% CI $0.6-1.8]$ per night) and severity (mean difference $1.3 \mathrm{~cm}$ [95\% CI 0.9-1.7] on 10-cm visual analog scale) of nocturnal leg cramps with nightly calf and hamstring stretches. ${ }^{8}$

Although there is consensus that quinine should not be used routinely for nocturnal leg cramps, a complete ban would be draconian. The Medicines and Healthcare Products Regulatory Agency in the United Kingdom provides sound practice advice, in my opinion. A four-week trial of quinine could be an option for fully informed patients experiencing frequent, severe cramps that disrupt their sleep, but only after treatable causes have been ruled out and nonpharmacologic measures have been shown to be ineffective. ${ }^{9}$ Trying potentially less toxic pharmacologic agents could be an option as well, although evidence supporting their efficacy is weak. ${ }^{3}$ During the trial, patients should be closely monitored and the quinine stopped after four weeks if there is no benefit. ${ }^{9}$ If treatment continues, patients should be followed and advised periodically (e.g., every three months) to try stopping the drug to reassess the benefit. A randomized controlled trial showed that advising patients to try stopping quinine temporarily was not associated with serious problems and led to a greater number stopping the agent (odds ratio of not taking quinine at 12 wk 3.32, 95\% CI 1.37-8.06) compared with patients not advised to stop it. ${ }^{10}$ The merit of a "quinine holiday" during the colder months, as suggested by Garrison and colleagues, becomes moot if patients are not prescribed the agent in the first place or are periodically advised to try stopping it.

\section{References}

1. Garrison SR, Dormuth CR, Morrow RL, et al. Seasonal effects on the occurrence of nocturnal leg cramps: a prospective cohort study. CMAJ 2015;187:248-53.

2. Brunton LL, Chabner BA, Knollmann BC, editors. Quinine and quinidine. In: Goodman \& Gillman's the pharmacological basis of therapeutics. 12th ed. New York: McGraw-Hill; 2011:1405-7.

3. Katzberg HD, Khan AH, So YT. Assessment: symptomatic treatment for muscle cramps (an evidence-based review) report of the Therapeutics and Technology Assessment Subcommittee of the American Academy of Neurology. Neurology 2010;74:691-6.

4. El-Tawil S, Al Musa T, Vali H, et al. Quinine for muscle cramps. Cochrane Database Syst Rev 2010;(12):CD005044.

5. Houstoun M, Reichman ME, Graham DJ, et al. Use of an active surveillance system by the FDA to observe patterns of quinine sulfate use and adverse hematologic outcomes in CMS Medicare data. Pharmacoepidemiol Drug Saf 2014;23:911-7.

6. Younger-Lewis C. Quinine sulfate and serious adverse reactions. Can Advers Reaction Newsl 2011;21(2):5. Available: www.hc-sc .gc.ca/dhp-mps/medeff/bulletin/carn-bcei_v21n2-eng.php\#a4 (accessed 2015 Jan. 16).

7. Blyton F, Chuter V, Walter KE, et al. Non-drug therapies for lower limb muscle cramps. Cochrane Database Syst Rev 2012. (1):CD008496

8. Hallegraeff JM, van der Schans CP, de Ruiter R, et al. Stretching before sleep reduces the frequency and severity of nocturnal leg cramps in older adults: a randomized trial. J Physiother 2012;58:17-22.

9. Quinine: not to be used routinely for nocturnal leg cramps. Drug Safety Update 2010;3:3.

10. Coppin RJ, Wicke DM, Little PS. Managing nocturnal leg cramps - calf-stretching exercises and cessation of quinine treatment: a factorial randomized controlled trial. $\mathrm{Br} \mathrm{J}$ Gen Pract 2005;55:186-91.

Affiliation: Brenda Strafford Foundation Chair in Geriatric Medicine, University of Calgary, Calgary, Alta. 